\title{
Laparoscopic cholecystectomy and endoscopic retrograde cholangiopancreatography for children with cholecystocholedocholithiasis
}

\author{
Safwat K, a MD; Ismaiel M Tantawy, a MD; Awni Elzeftawy, a MD; \\ Nawel Elsayed,a MD; Hosam Elsaadany, $h$ MD
}

a) Department of General Surgery, Zagazig University Hospitals, Egypt.

b) Pediatric Gastroenterology Unit, Zagazig University Hospitals, Egypt.

Co"espondence:e-mail: kh_sa.fwat@yahoo.com

Abstract

Purpose: Is to evaluate efficacy and safety of endoscopic retrograde cholangiopancretography $(E R C P)$ and laparoscopic cholecystectomy in children with calcular obstructive jaundice.

Materials and methods: Eleven children suffering.from calcular cholecystis with calcular obstructive jaundice were diagnosed and selected after completion of full laboratory and radiological investigations (work-up) in the period.from March 2005 till June 2010. They were admitted in Surgery Department Zagazig University Hospitals. All children underwent Endoscopic retrograde cholangiopancretography $(E R C P)$ to detect stone $(s)$ in biliary tree prior to laparoscopic cholecystectomy, and 9 of the 11 children also underwent endoscopic biliary drainage with stent placement in same session.In the other 2 patients' sludges and stone were cleared using basket forceps prior to laparoscopic cholecystectomy.

Results: ERCP was adequate in helping to predict biliary ductal stones and removal of them in all patients with no reported diagnostic or therapeutic failure. The stent placement was indicated in 9 of 11 (81.8\%) children, the other two children (18.2\%) underwent just stone extraction and clearance of biliary tree. Two to three weeks later laparoscopic cholecystectomy was successfully performed to all children with removal of stent after 2 to three weeks. There were reported complications in 3(27.3\%) cases, one (9\%) mild pancreatitis and 2 (18.3) fever after ERCP. There were no reported complications in the other 2 patients after laparoscopic cholecystectomy.

Conclusion: This study suggests that ERCP followed by laparoscopic cholecystectomy is the choice line of management in children with calcular obstructive jaundice and can be done safely with accepted complications.

\section{Introduction:}

Although still rare, pediatric cholelithiasis appears to have been on the rise since the early 1970s.I The causes of this increase are multifactorial and include an improved ability to detect gallstones as well as an actual increased incidence. Sickle cell disease is one of the common hemoglobinopathies.3-5 One of the common manifestations of Sickle cell disease is jaundice, which can be caused by a variety of hepatobiliary diseases including cholecystocholedecholithiasis.6-8 The frequency of cholelithiasis in patients with Sickle cell disease is variable, ranging from $4 \%$ to $55 \%$, and this increases with age.5-IO
Laparoscopic cholecystectomy (LC) has become the procedure of choice for children and adults, and open cholecystectomy is now performed only rarely.11 There has been a concomitant change in the management of common bile duct (CBD) stones. In adults, CBD exploration at the time of the initial operation has been replaced, for the most part, by preoperative or postoperative endoscopic retrograde cholangiopancreatography (ERCP).12,13 Its standard use in children, however, has been limited by technical difficulties, low incidence of pancreaticobiliary disease, and lack of knowledge of ERCP by pediatric surgeons and pediatricians. $1^{4}$ 
Pediatric ERCP is used as a therapeutic tool in addition to its diagnostic applications. The best approach for CBD stones in children is even less well defined)5,16 A combined endoscopic sphincterotomy (ES) with common stone extraction followed by laparoscopic cholecystectomy has been successfully reported in children.17 Choledocholithiasis is the most frequent biliary indication for ERCP in children. Such patients were treated by ES and stone removal with basket and or balloon extraction. Is

\section{Patients and methods:}

During the period from March 2005 till June 2010 children suffering from vague abdominal pain associated with attacks of fever, rigors and/or repeated attacks of jaundice presented to out patient clinic of pediatric gastroenterology unit and surgical department Zagazig University hospitals were examined. Out of them eleven children were selected; 4 females and 7 males. All of them had been diagnosed to have cholecystocholedocholithiasis and were included in this study. Diagnosis was based on clinical and biochemical evidence of jaundice and ultrasound. Their medical records were reviewed and the following information was obtained: Age, sex, clinical presentation, investigations, and abdominal ultrasound results.

All the eleven children were subjected to ERCP (using Pentax 402 ED3485T or Olympus JF1T20 duodenoscope) under general anesthesia in operative room with using of Carm (TCA4PLUS) for biliary visualization, endoscopic sphincterotomy, and stone extraction with stent insertion (7 French) in nine of them. All children were prepared for elective laparoscopic cholecystectomy (LC) within two to three weeks after ERCP. Two to three weeks after LC, stent removal under deep sedation (midazolam, ketamine, and fentanyl) in operation room was perfomed. An detailed informed and written consent was obtained from the parents or guardian of all children. This study was approved by our Internal Review Board. All ERCP findings, therapeutic procedures at the time of ERCP, findings of LC, complications and outcome were collected, reported and discussed.

\section{Results:}

Eleven children were included in this study; 7 males and 4 females their ages ranging from 27 months to 15 years with a mean, 6.76 years \pm 3.9 standard deviation. Sickle cell anemia was proved in only $2(18 \%)$, no specific cause could be detected in rest of children. All children were suffering of repeated attacks of abdominal colic according to their complaint or their parents telling. Attacks of vomiting and fever were reported in 6 patients $(54.5 \%)$ with leucocytosis in only 3 children $(27.2 \%)$. Clinical jaundice was detected in 9 children (81.8\%). Ultrasonographic evidence of calcular cholecystitis was proved inall patients, dilated CBD in $9(81.8 \%)$ of them and evident stone or more in 8 children $(72.7 \%)$. Biochemical tests proved hyperbulirubinemia, elevated alkaline phosphatase and elevated Gamma glutamyltransferase Table(l).

Table (1): Biochemichal results mean during study.

\begin{tabular}{|l|c|c|c|}
\hline \multicolumn{1}{|c|}{ Biochemical test } & before & $\begin{array}{c}\text { After } \\
\text { 3 weeks }\end{array}$ & $\begin{array}{c}\text { After } \\
\text { 6weeks }\end{array}$ \\
\hline Total bilirubin & 3.7 & 1.8 & 0.9 \\
\hline Direct bilirubin & 2.7 & 0.4 & 0.2 \\
\hline Alkkaline phosphatase & 556.1 & 111.7 & 100.2 \\
\hline Gamma glutamyltransferase & 127.9 & 51 & 38.3 \\
\hline
\end{tabular}


ERCP Figure(1) was done for all children, choledocholithaisis was detectedin 10 (90.90Al) while mud and flakes inonly one of the children (9\%).ES Figure(1) was done for all children and a stent inserted in 9 of them $(81.8 \%)$, in the other $2(18 \%)$, clearance ofbile ducts using basket forceps and/or balloon Figure(3) was enough. A 7 French plastic stent Figure(4), was placed in $9(81.8 \%)$ patients with cholangiographic evidence of a patent cystic duct and presence of multiple stones in the gallbladder. All patients underwent laparoscopic cholecystectomy Figure(5), 2-3 weeks after ERCP and after biochemical tests returned towards normal as seen in Table(1).
2-3 weeks later the stent was removed after biochemical tests and ultrasonographic examination were normal Table(1). The total complications were reported in 3 children one with mild biliary pancreatitis, and 2 with controllable fever. All complications were controlled by medical treatment with no reported deaths or serious complications in the early 6 month of follow-up. There was no specific cause evident in this study, only hemolytic disease disorder (Sickle cell disease) was evident in 2 children. All children were followed-up in gastroenterology surgical and pediatric outpatient units.

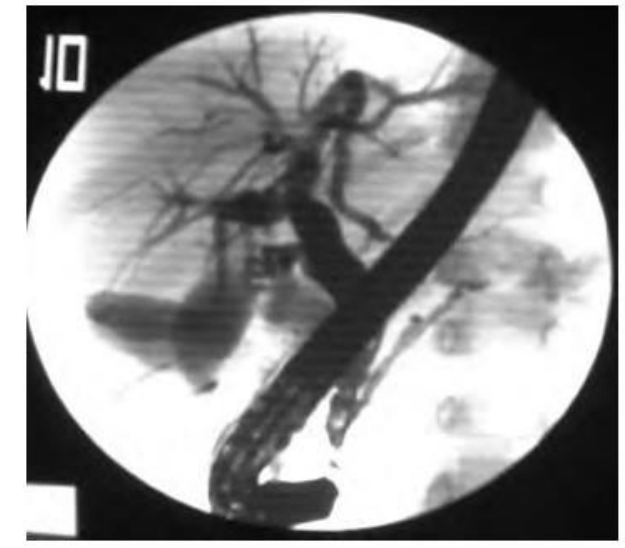

Figure (1): ERCP showing multiple stones.

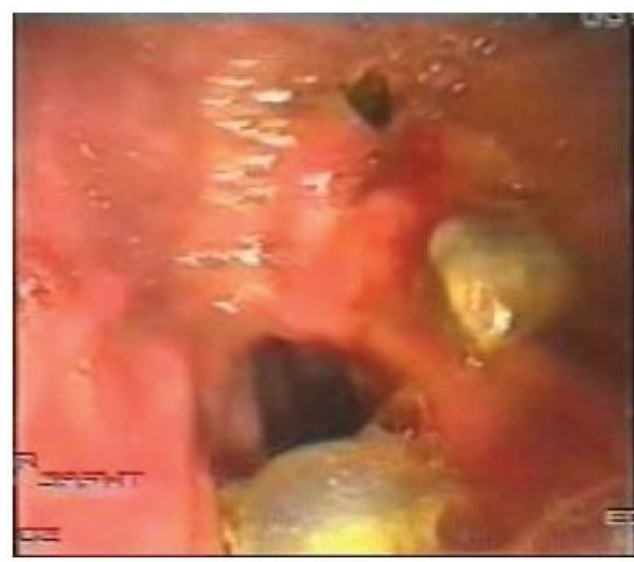

Figure (3): Showing stone clearance using balloon.

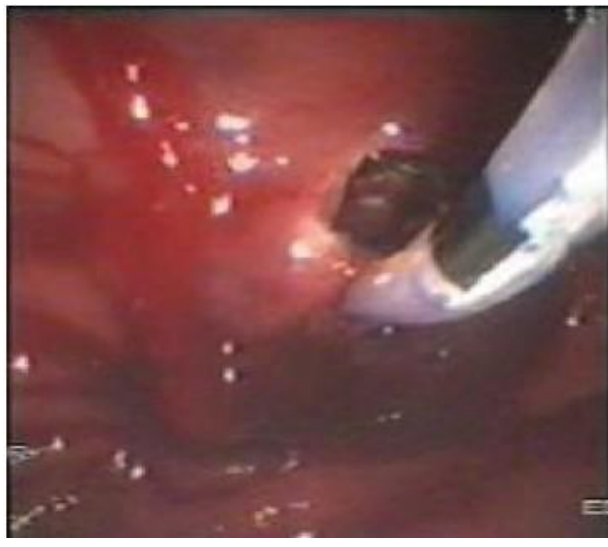

Figure (2): Showing sphincterotomy of the papilla.

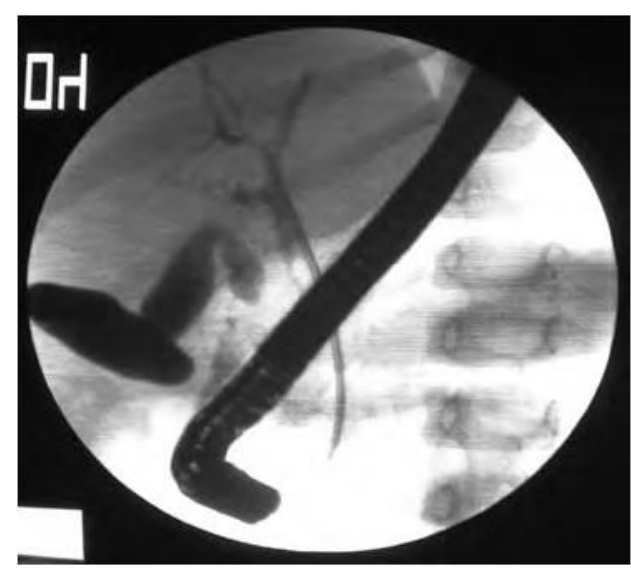

Figure (4): Showing stent in biliary tree. 


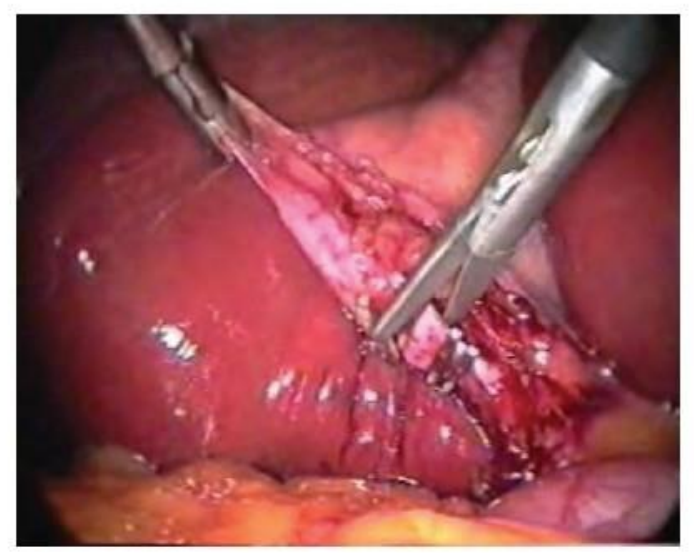

Figure (5): Showing clipping and cutting of cystic duct.

\section{Discussion:}

The incidence of gallstones in children increased in these last years due to the regular use of the noninvasive detection technique (ultrasonography). ERCP has become a new diagnostic and therapeutic modality in children with choledocholithiasis. These patients were treated by endoscopic sphincterotomy and stone removaJ)S,19 In this study we selected eleven children with colecystocholedecholithiasis. ERCP indication was choledocholithiasis either due to sickle cell anemia in only 2 cases (18\%) or due to non specific cause in 9 cases $(82 \%)$. The most common indications for ERCP in Western children are choledocholithiasis and pancreatitis.t5,t9 Indications differ in Asian countries.t8,20,21For example, in Saudi Arabia the most common indication was choledocholithiasis in patients with sickle-cell anemia,t8 whereas indication in Japan and India was mostly cbolodecal cyst20,21 All the procedures were done in one session; the canulation and papillotomy were done smoothly and there was no need to repeat ERCP: The slight difference in results from reported studieslS, 18,22,23 could be due to selected limited nwnber of cases in our study.

Almost all the patients with obstructive jaundice with stone/sludge; were treated by endoscopic sphincterotomy, stone removal using basket forceps or balloon and stent insertion in $9(82 \%)$ of thein the other 2 cases $(18 \%)$ there was no indication to insert stent as gall bladder was not visualized during ERCP.Mild elevation in serum amylase and lipase was reported in only one child (90/0) and low grade fever in 2 children (18\%) post ERCP. They recovered early on medical treatment. It is reported that intervention with ERCP may be a useful treatment modality in pancreatitis.23,24 We found that ERCP helped to improve associated inflammation, and offered relief of acute symptoms, jaundice and early relief of developed case of pancreatitis. For this purpose, we performed indwelling stent implantation in most of cases prior to LC.

Early laparoscopic cholecystectomy was done for all cases 2-3 weeks after biochemical results came to normal to avoid complications specially biliary pancreatitis. As others showed that in children with cholelithiasis awaiting surgery the risk of developing complications is high and that their occurrence affects significantly the preoperative and postoperative course.2S-28 We had noreportedcomplications or morbidity in our results as we did not include emergent LC as reported by others.13,25,28 The stent was removed after 2-3 weeks after LC under deep sedation with no reported complications. All children were followed up for six months in outpatient clinic with biochemical tests and abdominal ultrasound with no reported problems.

In conclusion, the encouraging results of this study recommend that children with cholecystocholedocholithiasis should be treared by endoscopic CBD stone or sludges removal and subsequent laparoscopic cholecystectomy for gallbladder stones to prevent the potential complications of cholecystitis and 
choledocholithiasis which lead to major risks, discomfort, and repeated hospitalization.

References:

1- Bailey PV, Connors RH, Tracy TF Jr, SoteloAvila C, Lewis JE, Weber TR: Changing spectrum of cholelithiasis and cholecystitis in infants and children. Am JSurg 1989; 158: 585-588.

2- Waldhausen JHT, Benjamin DR: Cholecystectomy is becoming an increasingly common operation in children. Am J Surg 1999; 177: 364-367.

3- Perrine RP, Pembrey ME, John P, Perrine S, Shoup F: Natural history of sickle cell anemia in Saudi Arabs. A study of 270 subjects. Ann Intern Med 1978; 88: 1-6.

4- Pembrey ME, Perrine RP, Wood WG, Weatherall DJ: Sickle beta 0 thalassemia in Eastern Saudi Arabia.Am JHum Genet 1980; 32: 26-41.

5- Al-Awamy BH: Sickle cell anemia, its clinical manifestations and their management. Saudi Med J1987; 9: 553562.

6- Banerjee S, Owen C, Chopra S: Sickle cell hepatopathy. Hepatology 2001; 33: 10211028.

7- Koullapis N, Kouroupi IG, Dourakis SP: Hepatobiliary manifestations of sickle cell disease. Haema 2005; 8: 393-404.

8- Al-Salem AH, Qaisarruddin S, Al-Dabbous I, Bhamidipati P, Abusrair H, A-mman H, AI Jam'a A: Cholelithiasis in children with sickle cell disease. Pediatr Surg Int 1996; 11: 471-473.

9- Rennels MB, Dunne MG, Grossman NJ, Schwartz AD: Cholelithiasis in patients with major sickle hemoglobinopathies. Am J Dis Child 1984; 138: 66-67.

10-Sarnaik S, Slovis TL, Corbett DP, Emami A, Whitten CF: Incidence of cholelithiasis in sickle cell anemia using the ultrasonic gray-scale technique.JPediatr 1980; 96: 1005-1008.

11-Ellison EC, Carey LC: Cholecystostomy, cholecystectomy and intraoperative evaluation of the biliary tree. In: Mastery of Surgery. BakerRJ, Fischer JE (Editors); Philadelphia, Pa: Lippincott Williams \& Wilkins (Publisher); 2001; 1142-1151. 12-Newman KD, Powell DM, Holcomb GW
Ill:The management of choledocholithiasis in children in the era of laparoscopic cholecystectomy. JPediatr Surg 1997; 32: 1116-1119.

13-Waldhausen JHT, Graham DD, Tapper D: Routine intraoperative cholangiography during laparoscopic cholecystectomy minimizes unnecessary endoscopic retrograde cholangiopancreatography in children. JPediatr Surg 2001; 36: 881884.

14-HsuRK,Draga novP,LeungJW, Tamasky PR, Yu AS, Hawes RH, Cunningham JT, Cotton PB: Therapeutic ERCP in the management of pancreatitis in children. Gastrointest Endosc 2000; 51: 396-400.

15-Cheng CL, Fogel EL, Sherman S, McHenry L, Watkins JL, Croffie JM, Gupta SK, Fitzgerald JF, Lazzell-Pannell L, Schmidt S, Lehman GA: Diagnostic and therapeutic endoscopic retrograde cholangiopancreatography in children: A large series report.J Pediatr Gastroenterol Nutr 2005; 41: 445-453.

16-Varadarajulu S, Wilcox CM, Hawes RH, Cotton PB: Technical outcomes and complications of ERCP in children. Gastrointest Endosc 2004; 60: 367-371.

17-Guelrud M, Zambrano V, Jaen D, et al: Endoscopic sphincterotomy and laparoscopic cholecystectomy in a jaundiced infant Gastrointest Endosc 1994; 40:99-102.

18-Issa H, Al-Haddad A, Al-Salem AH: Diagnostic and therapeutic ERCP in the pediatric age group. Pediatr Surg Int 2007; 23: 111-116.

19-Pfau PR, Chelimsky GG, Kinnard MF, Sivak MV Jr, Wong RC, Isenberg GA, Gurumurthy P, Chak A: Endoscopic retrograde cholangiopancreatography in children and adolescents. J Pediatr Gastroenterol Nutr 2002; 35: 619-623.

20-Poddar U, Thapa BR, Bhasin DK, Prasad A, Nagi B, Singh K: Endoscopic retrograde cholangiopancreatography in the management of pancreaticobiliary disorders in children.JGastroenterol Hepatol2001; 16: 927-993.

21-Teng R, Yokohata K, Utsunomiya N, Takahata S, Nabae T, Tanaka M: Endoscopic retrograde 
cholangiopancreatography in infants and children.J Gastroenterol2000; 35: 39-42.

22-Issa H, Al-Haddad A, Al-Salem AH:Sickle cell cholangiopathy: An endoscopic retrograde cholangiopancreatography evaluation. World J Gastroentero/2009; 15(42): 5316-5320.

23-Jang $N$, Yoon $\mathrm{CH}$, Kim KM: Endoscopic retrograde cholangiopancreatography in pancreatic and biliary tract disease in Korean children. World J Gastroenterol 2010; 16(4): 490-495.

24-Choi BH, Lim YJ, Yoon CH, Kim EA, Park YS, Kim KM: Acute pancreatitis associated with biliary disease in children. J Gastroenterol Hepatol2003; 18: 915921.

25-Curro G, Meo A, Ippolito D, Pusiol A, Cucinotta E: Asymptomatic cholelithiasis in children with sickle cell disease: Early or delayed cholecystectomy? Ann Surg 2007; 245(1): 126-129.

26-Marchant WA, Walker I: Anaesthetic management of the child with sickle cell disease. Paediatr Anaesth 2003; 13: 473489.

27-SeleemiM, Al-Hashemy AM, MeshrefSS: Mini-laparoscopic cholecystectomy in children under 10 years of age with sickle cell disease. Aust NZ JSurg 2005; 75:562565.

28-0tto AK, Neal MD, Slivka AN, Kane TD: An appraisal of endoscopic retrograde cholangiopancreatography (ERCP) for pancreaticobiliary disease in children: Our institutional experience in 231 cases. Surg Endosc 2011; 27: 1582-1588. 